\title{
Advanced Necrotizing Enterocolitis Part 1: Mortality
}
M. Thyoka ${ }^{1}$ P. de Coppi ${ }^{1}$
K. Cross ${ }^{1}$
A. Pierro ${ }^{1}$
S. Eaton ${ }^{1}$
K. Khoo ${ }^{1}$
N.J. Hall ${ }^{1}$ J. Curry ${ }^{1}$
E. Kiely ${ }^{1}$
D. Drake ${ }^{1}$

${ }^{1}$ Department of Surgery, Great Ormond Street Hospital and UCL Institute of Child Health, London, United Kingdom

Address for correspondence and reprint requests Agostino Pierro, M.D. F.R.C.S., F.A.A.P., Department of Paediatric Surgery, UCL Institute of Child Health, 30 Guilford Street, London WC1N 1EH, United Kingdom Eur J Pediatr Surg 2012;22:8-12. (e-mail: a.pierro@ich.ucl.ac.uk).

\begin{abstract}
Aim of the Study The aim of this study was to investigate the factors associated with mortality in infants referred for the surgical treatment of advanced necrotizing enterocolitis (NEC).

Methods Retrospective review of all infants with confirmed (Bell stage II or III) NEC treated in our unit during the past 8 years (January 2002 to December 2010). Data for survivors and nonsurvivors were compared using Mann-Whitney test and Fisher's exact test and are reported as median (range).

Results Of the 205 infants with NEC, 35 (17\%) were medically managed; $170(83 \%)$ had surgery; 66 (32\%) infants died; all had received surgery. Survivors and nonsurvivors were comparable for gestational age, birth weight, and gender distribution. Overall mortality

Keywords

- necrotizing enterocolitis

- mortality

- multiple organ dysfunction syndrome was $32 \%$, the highest mortality was in infants with pan-intestinal disease $(86 \%)$ but remained significant in those with less severe disease (multifocal $39 \%$; focal disease $21 \%$ ). The commonest cause of mortality was multiple organ dysfunction syndrome and nearly half of the nonsurvivors had care withdrawn.

Conclusion Despite improvement in neonatal care, overall mortality (32\%) for advanced NEC has not changed in 10 years. Mortality is significant even with minimal bowel involvement.
\end{abstract}

\section{Introduction}

Necrotizing enterocolitis (NEC) remains a devastating disease affecting newborn infants and is often associated with significant mortality and morbidity, especially in the very preterm and extremely low birth weight (ELBW) infants. ${ }^{1,2}$ The mortality rates are high particularly in those infants requiring surgical intervention. ${ }^{3}$ At laparotomy, the extent of disease varies from focal disease to multifocal or pan-intestinal disease, affecting varying lengths of bowel. ${ }^{3,4}$ Previous reports have shown mortality rates increasing with more advanced and extensive disease. ${ }^{4}$ While advances in perinatal care have contributed to an improvement in survival of extremely premature and ELBW infants, the mortality in infants with NEC has remained high despite advances in

received

May 15, 2011

accepted after revision

December 6, 2011 both medical and surgical treatment. ${ }^{5,6}$ The aim of this study was to characterize the factors associated with mortality in infants with NEC referred to our unit.

\section{Materials and Methods}

With institutional ethical approval, we reviewed case notes of all infants with confirmed (Bell stage II or III) NEC treated in our unit during the past 8 years (January 2002 to December 2010). NEC was defined by Bell's criteria, as modified by Kliegman and Walsh. ${ }^{7,8}$ Data retrieved included demographic, clinical, radiological, and operative details. Using mortality as our main outcome, we compared two groups (survivors and nonsurvivors) for factors predicting mortality. Data were compared using Mann-Whitney test,
Copyright $\odot 2012$ by Thieme Medical Publishers, Inc., 333 Seventh Avenue, New York, NY 10001, USA. Tel: +1(212) 584-4662.
DOI http://dx.doi.org/ 10.1055/s-0032-1306263. ISSN 0939-7248. 


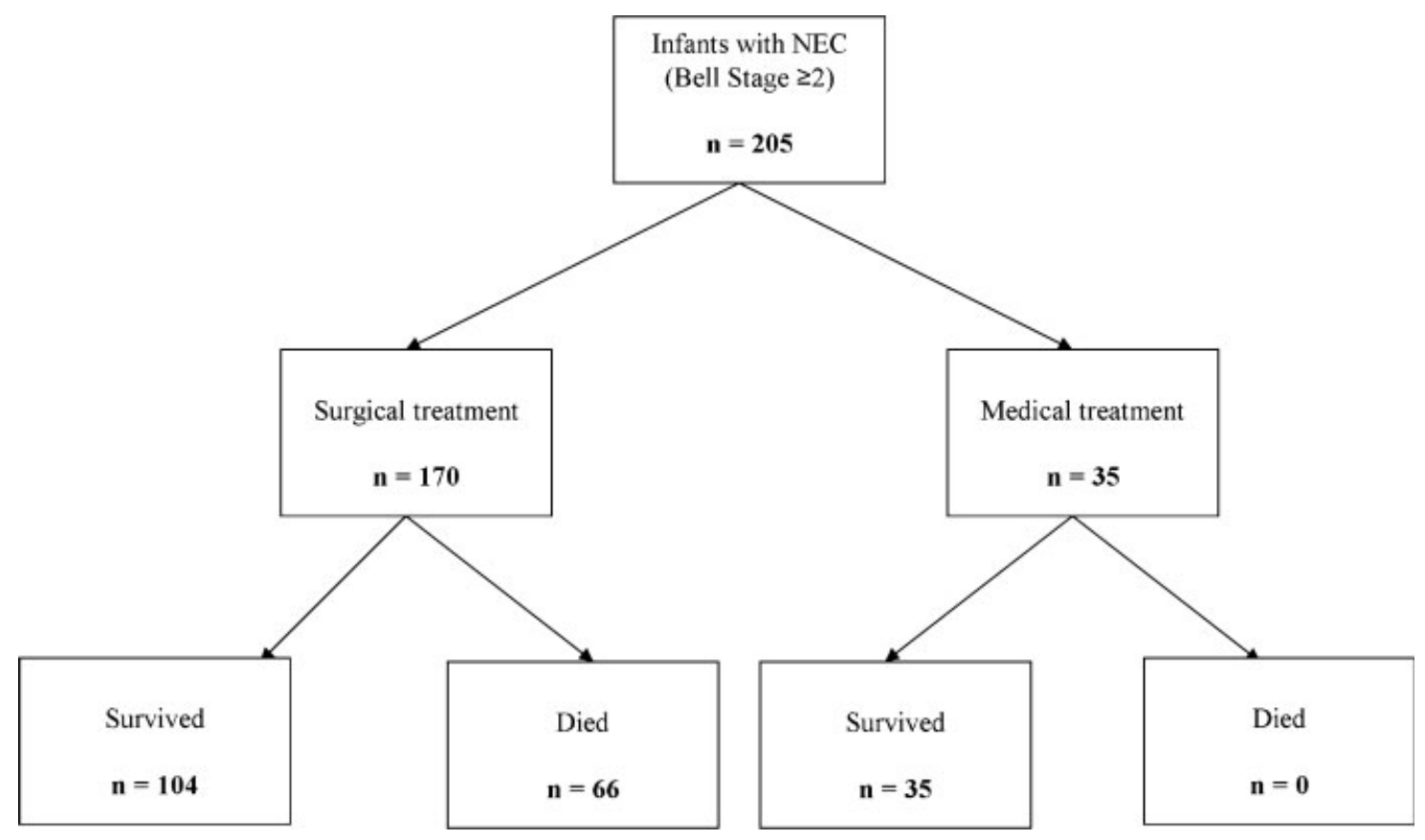

Figure 1 Cohort of NEC infants.

Fisher's exact test, and chi-square test as appropriate. Binary logistic regression analysis was also performed to determine the effect of predictors of mortality. Data reported as median (range), and the level of significance was set at $p<0.05$.

\section{Results}

During the study period (2002 to 2010), 205 infants with confirmed NEC (Bell stage II or III) were admitted to our unit for further surgical evaluation. Of these, 35 (17\%) were managed medically and 170 (83\%) required operative intervention.

The overall mortality rate was $32 \%$. All deaths $(n=66)$ occurred in infants who had surgery for NEC, giving a mortality following surgery for NEC of $39 \%$. Mortality was significantly higher in infants receiving surgery compared with those receiving medical treatment ( $p<0.0001$, - Fig. 1 ).

There was no significant difference, using Mann-Whitney test, Fisher's exact test, or binary logistic regression analysis, between survivors and nonsurvivors in terms of birth weight, gestational age, or gender distribution ( - Table 1, - Fig. 2). Of the 170 infants receiving surgery, there was a significant difference in the extent of intestinal involvement between those who died and those who survived (-Table 2). Those who died had a significantly higher incidence of more extensive intestinal involvement $(p<0.0001)$ as indicated by a higher proportion of patients of pan-intestinal involvement (29\% in the on-survivors vs. $3 \%$ in the survivors) and a lower proportion with focal disease (-Fig. 3A). The majority of infants undergoing surgery had a primary laparotomy ( $n=161 ; 95 \%)$; nine infants (5\%) had peritoneal drain (PD) insertion as the first procedure as part of a previously reported randomized controlled trial. ${ }^{9}$ All those receiving PD required a subsequent laparotomy for clinical deterioration (-Table 3 ).

Cause of death is summarized in -Table 4. Among nonsurvivors, $32 / 66$ (48\%) of the deaths followed a decision to withhold or withdraw intensive care. In the infants who had care withdrawn, most (15 [47\%]) had care withdrawn due to multiple organ dysfunction syndrome (MODS) refractory to

Table 1 Characteristics of Infants with NEC: Survivors and Nonsurvivors

\begin{tabular}{|l|l|l|l|}
\hline & Survivors & Nonsurvivors & $\boldsymbol{p}$ Value \\
\hline & $\boldsymbol{n}=139$ & $\boldsymbol{n}=66$ & \\
\hline Birth gestational age $(\mathrm{wk})$ & $27(22-42)$ & $27(23-42)$ & 0.62 \\
\hline Corrected gestational age (wk) & $32(24-137)$ & $32(23-47)$ & 0.63 \\
\hline Birth weight $(\mathrm{kg})$ & $0.92(0.40-4.72)$ & $0.96(0.48-3.43)$ & 0.50 \\
\hline Admission weight $(\mathrm{kg})$ & $1.28(0.58-4.40)$ & $1.30(0.52-3.45)$ & 0.95 \\
\hline Gender, male $[\mathrm{n}(\%)]$ & $80(58)$ & $42(65)$ & 0.45 \\
\hline
\end{tabular}

Data reported as median (range) or number (percentage); $p<0.05$. 


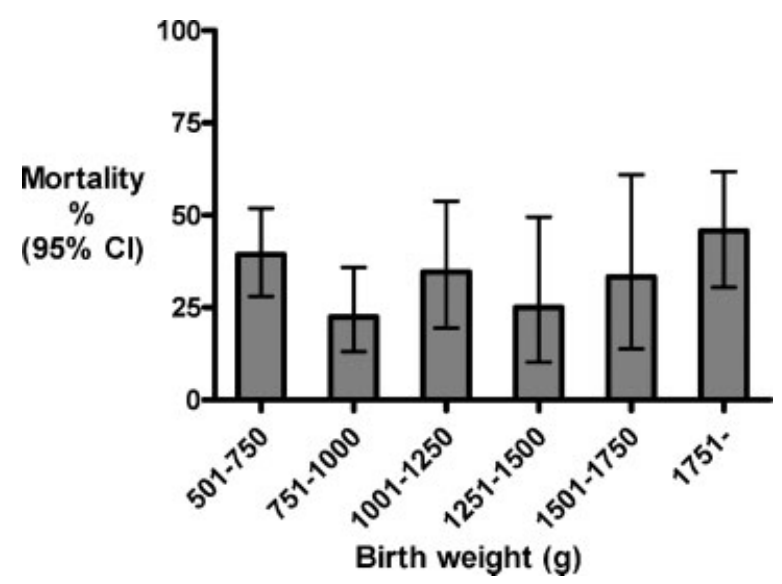

Figure 2 Mortality by birth weight.

maximal medical treatment with presumed poor outcome and $4(13 \%)$ because of NEC totalis and the decision not to perform surgical resection of the entire gastrointestinal tract ( - Table 4). A total of 34 infants died without care being actively withdrawn, predominantly from MODS or sepsis.

\section{Discussion}

Mortality rates among infants treated for NEC remains high, especially among ELBW infants, those requiring surgery and those with multiorgan failure. ${ }^{1,3}$ As more extremely premature and low birth weight infants survive with improved perinatal care, the population of infants with risk factors for development of NEC increases. In parallel with these trends, advances in preventive, medical, and surgical treatment of NEC have failed to appreciably reduce the mortality rates in infants with NEC. ${ }^{10,11}$

Fitzgibbons et al, using data from Vermont Oxford Network showed a trend of increasing mortality from NEC with decreasing birth weight categories; the highest mortality (42\%) observed in infants weighing 500 to $750 \mathrm{~g} .{ }^{12}$ In our study patients there was no significant association between birth weight, admission weight, birth gestational age or corrected gestational age, and mortality. This apparent contradiction may be due to the following reasons: (1) exclusion of suspected NEC (Bell stage I) in our study; (2) the inclusion in our study of only infants referred for surgical assessment rather than all infants with NEC; and (3) in our institution, we use the same criteria for surgical treatment in extremely premature infants, whereas other centers may consider ex-

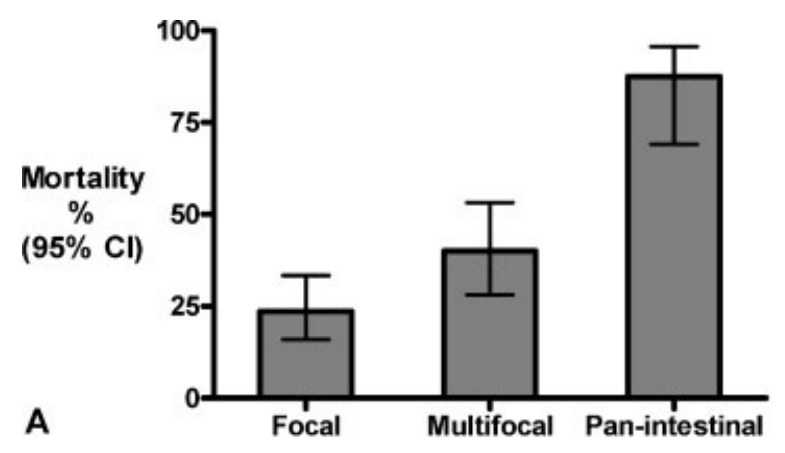

Chi square; $p<0.0001$

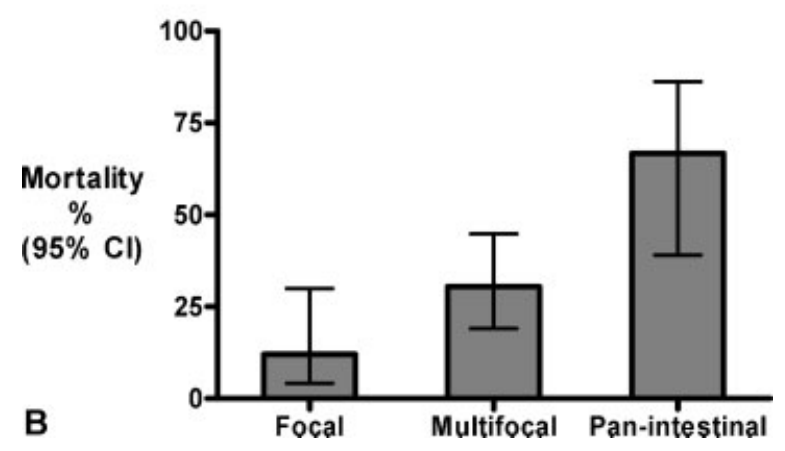

Figure 3 (A) Extent of disease and mortality. (B) Mortality by extent of disease in 1986 to 1996 . Data redrawn from Fasoli et al. ${ }^{4}$

treme prematurity as a contraindication for laparotomy. This is reflected in our series in which there is preponderance for surgery in infants with NEC in contrast to other series.

In this study, we have shown that overall mortality in infants with confirmed NEC remains high, and these rates mirror the extent of disease found at laparotomy, with highest rates among infants with pan-intestinal disease. ${ }^{13}$ This concurs with our unit's published previous experience where Fasoli et al ${ }^{4}$ showed overall mortality rate of $30 \%$, the highest mortality (67\%) occurring in the infants with pan-intestinal disease (-Fig. 3B). This may be because either (1) there has been no improvement in the treatment of infants with NEC or (2) we are now referred sicker infants with NEC. It is notable that there remains a significant mortality rate $(21 \%)$ in the infants with less extensive, focal NEC. This may signify that extent of disease alone may not be the only factor affecting mortality.

Table 2 Extent of Disease at Laparotomy

\begin{tabular}{|l|l|l|l|}
\hline & Survivors & Nonsurvivors & $p$ Value \\
\hline & $n=105$ & $n=65$ & \\
\hline Focal, $n(\%)$ & $68(65)$ & $21(32)$ & $<0.0001$ \\
\hline Multifocal, $n(\%)$ & $34(32)$ & $22(34)$ & $22(34)$ \\
\hline Pan intestinal, $n(\%)$ & $3(3)$ & 22 & \\
\hline
\end{tabular}

Data reported as number (percentage); $p<0.05$. 
Table 3 Infants Who Underwent Surgery $(n=170)$

\begin{tabular}{|l|l|l|}
\hline Procedure & $\begin{array}{l}\text { Survivors } \\
(n=104)\end{array}$ & $\begin{array}{l}\text { Nonsurvivors } \\
(n=66)\end{array}$ \\
\hline Laparotomy & $(n=99)$ & $(n=62)$ \\
\hline Stoma ( \pm bowel resection) & 59 & 31 \\
\hline Anastomosis & 42 & 20 \\
\hline Open and close & 1 & 11 \\
\hline Clip and drop & 2 & 2 \\
\hline Peritoneal drain & $(n=5)$ & $(n=4)$ \\
\hline Drain alone & 0 & 0 \\
\hline Drain followed by laparotomy & & \\
\hline Stoma & 4 & 3 \\
\hline Anastomosis & 1 & 0 \\
\hline Open and close & 0 & 1 \\
\hline
\end{tabular}

Table 4 Cause of Death

\begin{tabular}{|l|l|}
\hline Reason & $n$ \\
\hline Following withdrawal of care & 32 \\
\hline Multiorgan failure & 15 \\
\hline Open and close (NEC totalis) & 4 \\
\hline Single organ failure & 8 \\
\hline Neurological (IVH: $n=2$, infarction: $n=1)$ & 3 \\
\hline Disseminated coagulopathy & 1 \\
\hline Others & 1 \\
\hline Not following withdrawal of care & 34 \\
\hline Multiorgan failure & 11 \\
\hline Sepsis & 9 \\
\hline Profound bleeding & 7 \\
\hline Cardiac arrest & 3 \\
\hline Single organ failure & 4 \\
\hline
\end{tabular}

IVH, intraventricular hemorrhage.

Nearly half of nonsurvivors had care withdrawn, mainly as a result of MODS. This is a particular group where the decision to withdraw care followed multidisciplinary meeting involving neonatal intensive care team, pediatric surgeon, and parents. In this particular group, no post mortem studies were requested by the coroner, and therefore we could not further substantiate extent of disease progression following withdrawal of care. Similarly, the infants with NEC totalis $(n=4)$ who had care withdrawn based on the fact that surgery was deemed not feasible with survival. These infants had an "open and close" laparotomy with no bowel resection.

Although this study is also limited by its retrospective nature, we have shown that despite the advances in the neonatal and surgical care of infants with NEC over the past decade, the mortality for advanced NEC has not changed in a single tertiary referral center. There is a desperate need to improve survival through preventive remedies such as breast milk promotion, judicious introduction and advancement of enteral feeds, probiotic therapy, ${ }^{14,15}$ as well as novel therapeutic interventions such as therapeutic hypothermia ${ }^{16}$ and stem cell therapy ${ }^{17}$ in vulnerable, at-risk groups.

\section{Conclusion}

Despite improvement in neonatal care, overall mortality (32\%) for advanced NEC has not changed in the past 10 years. Mortality, while highest in infants with extensive NEC, is significant even with minimal bowel involvement. In those infants with definite NEC, mortality does not appear to be related to low birth weight or prematurity. The commonest cause for mortality due to NEC is MODS. Further attempts at prevention of NEC and treatment of established disease are desperately needed.

\section{Conflict of Interest}

None

\section{References}

1 Lin PW, Stoll BJ. Necrotising enterocolitis. Lancet 2006;368 (9543):1271-1283

2 Kim SS, Albanese GT. Necrotizing enterocolitis. In: Grosfeld JL, O'Neill JA, Coran AG, Fonkalsrud EW, eds. Pediatric Surgery. Vol. 2. Philadelphia, PA: Mosby; 2006;1427-1452

3 Pierro A. The surgical management of necrotising enterocolitis. Early Hum Dev 2005;81(1):79-85

4 Fasoli L, Turi RA, Spitz L, Kiely EM, Drake D, Pierro A. Necrotizing enterocolitis: extent of disease and surgical treatment. J Pediatr Surg 1999;34(7):1096-1099

5 Rees CM, Eaton S, Pierro A. Trends in infant mortality from necrotising enterocolitis in England and Wales and the USA. Arch Dis Child Fetal Neonatal Ed 2008;93(5):F395-F396

6 Rees CM, Eaton S, Pierro A. National prospective surveillance study of necrotizing enterocolitis in neonatal intensive care units. J Pediatr Surg 2010;45(7):1391-1397

7 Bell MJ, Ternberg JL, Feigin RD, et al. Neonatal necrotizing enterocolitis. Therapeutic decisions based upon clinical staging. Ann Surg 1978;187(1):1-7

8 Kliegman RM, Walsh MC. Neonatal necrotizing enterocolitis: pathogenesis, classification, and spectrum of illness. Curr Probl Pediatr 1987;17(4):213-288

9 Rees CM, Eaton S, Kiely EM, Wade AM, McHugh K, Pierro A. Peritoneal drainage or laparotomy for neonatal bowel perforation? A randomized controlled trial. Ann Surg 2008;248(1):44-51

10 Holman RC, Stehr-Green JK, Zelasky MT. Necrotizing enterocolitis mortality in the United States, 1979-85. Am J Public Health 1989;79(8):987-989

11 Horbar JD, Badger GJ, Carpenter JH, et al; Members of the Vermont Oxford Network. Trends in mortality and morbidity for very low birth weight infants, 1991-1999. Pediatrics 2002;110(1 Pt 1):143151

12 Fitzgibbons SC, Ching Y, Yu D, et al. Mortality of necrotizing enterocolitis expressed by birth weight categories. J Pediatr Surg 2009;44(6):1072-1075, discussion 1075-1076

13 Alexander F, Smith A. Mortality in micro-premature infants with necrotizing enterocolitis treated by primary laparotomy is independent of gestational age and birth weight. Pediatr Surg Int 2008;24(4):415-419 
12 Advanced Necrotizing Enterocolitis Part 1 Thyoka et al.

14 Deshpande GC, Rao SC, Keil AD, Patole SK. Evidence-based guidelines for use of probiotics in preterm neonates. BMC Med 2011;9:92

15 Alfaleh K, Anabrees J, Bassler D. Probiotics reduce the risk of necrotizing enterocolitis in preterm infants: a meta-analysis. Neonatology 2010;97(2):93-99
16 Hall NJ, Eaton S, Peters MJ, et al. Mild controlled hypothermia in preterm neonates with advanced necrotizing enterocolitis. Pediatrics 2010;125(2):e300-e308

17 Zani A, Cananzi M, Eaton S, Pierro A, De Coppi P. Stem cells as a potential treatment of necrotizing enterocolitis. J Pediatr Surg 2009;44(3):659-660 